\title{
Nicole Brossard y la transferencia
}

Blanca Escudero de Arancibia

Universidad Nacional de Cuyo

Cuando se enfoca la obra brossardiana, es más común encontrarla relacionada con la transgresión que con el término que estoy utilizando. No es difícil encontrar este tipo de ligazón, teniendo en cuenta absolutamente todo: género (genre y gen$d e r$ ), política feminista a ultranza, paisajes y ecos de lugares o de voces, desdoblamiento del protagonismo, entre otras varias facetas. Mi objetivo es seguir un proceso de transferencia en el sentido etimológico y teórico del término en el conjunto de su obra. Por lo pronto, deberé cuidar mucho el vocabulario a usar por razones "globalizadas": lo que sea "políticamente correcto" hablando de quien estoy hablando.

Brossard produce (o crea) una de las mayores escrituras canadienses contemporáneas. Si digo "es una de las mayores 'escritoras"', le estoy recortando la valoración de la que hoy es miembro de la Academia Mundial de Poesía ${ }^{1}$ le estoy, justamente, fabricando un locus, un rincón, una habitación woolfiana. Para decirlo con más precisión, la escritura de Brossard es una permanente dis-locación, multiplicación de lugares, errancia del yo entre seres y sitios. Búsqueda descentrada de la identidad, diferancia de su diferencia, el pivote de sus textos es la deriva, palabra clave en su teoría y en sus ficciones, sean éstas novelescas ${ }^{2}$, poéticas o teatrales.

Originalmente, el concepto de transferencia tiene tanto que ver con la fuente latina (transferre: llevar o conducir más allá, o a otro lado) como con el campo de lo financiero. En francés, sólo puedo hablar de transfert, lo que evoca de inmediato el dinero; en nuestra lengua, el término es simbólicamente más abarcador. Ahora bien, los textos de Brossard labran la lengua y las lenguas como acto amoroso, de contacto, que permite también el viaje, el traspaso de fronteras, en la misma medi$\mathrm{da}$ en que en sus poemas, ensayos y novelas hay una deriva ${ }^{3}$ en territorios que le permiten, por ejemplo, epigrafiar su Baroque d'aube con Samuel Beckett y nuestra Alejandra Pizarnik. El juego simbólico, tanto con los espacios como con los nombres, exige una lectura densa, que transfiere la escritura teórica más contemporánea a los valores analógicos y alegóricos que llevan el tiempo hacia el pasado de oro.

Así, en Baroque d'aube, los nombres de los personajes significan, al mejor estilo decimonónico y/o medieval: Cybil Noland es la negación misma de la transferencia en cuanto a la desterritorialización más radical, una sibila de ninguna parte ${ }^{4}$; Sixtine, que juega con lo gráficamente escrito y con la transferencia del oído a otra lengua (sixteen), la oceanógrafa Occident DesRives (sonido dérive...). En Picture Theory, Claire Dérive vive entre dos lenguas, transfiriendo su acción del francés al inglés y viceversa, y reconociendo en su entorno la multiplicidad de transportes identitarios.

Lo mismo sucede con los lugares: como ocurre con los personajes -tanto por su 
nombre como por sus "historias"-, los sitios se entrelazan y son, siempre, fronteras movedizas entre el mapa y el imaginario, transferencia perpetua, como se puede ver fácilmente en Picture... (pp. 50-51, entre otras).

Para Brossard, la necesidad del desplazamiento está obligada por la memoria y asociada al agua: maternidad, mar, lugares líquidos y misteriosos que responden sólo a la mujer: "A la orilla del mar, el tiempo es arena".

La escritura es esencialmente (valga la paradoja para una feminista "posteórica") un trabajo sobre la/s lengua/s que la visten: la mallarmeana tarea sobre los sonidos, los símbolos y la teoría hace muy difícil la traducción de cualquiera de sus textos sin pérdida. La versión castellana Instalaciones (con y sin pronombres), como también El desierto malva y el espléndido y difícil En el presente de la pulsación que editó Botella al Mar son desafíos que permiten transferir sólo alguna de las numerosas capas de sentido. Necesidad de la autora al lado del lector: ésa es la experiencia de lectura de sus poemas, desnudos de toda puntuación, campo abierto a ningún horizonte preciso. ${ }^{6}$

Esta poesía es, por supuesto, transgresión en cuanto a la lógica (masculina) ${ }^{7}$, la sintaxis y la gramática (leyes, reglamentos) ${ }^{8}$, la ortografía", las posibles "escuelas" y la historia "oficial"; es también invasión de lo poético en toda forma literaria ${ }^{10}$, hibridez total aun en las páginas-sábana de la "teoría/ficción” y en el uso de los -a veces-inexplicables blancos en la página. ¿¿ónde termina lo poético, dónde anida la narración en los textos brossardianos? Los géneros se transfieren, y aunque una de las frases leit motiv de sus textos es "relatar no es asunto mío" y aún en la resistencia a la prosa como comunicación con el referente, su novela es construcción poética y gráfica, como sus poemas, están relacionados, a veces claramente, con elementos autobiográficos que esquivan la comunicación autor-lector. La razón es que "[e]n un decorado patriarcal binario decadente, el sujeto vive rodeado de personajes y de nadie". ${ }^{11}$

Ésa es la razón para que en la obra de esta feminista, los yoes femeninos se transfieran alternativamente la visión y la acción del yo-escritora. La visión, lo visto, la mirada, el ojo son fundamentales para Brossard. En el mejor ejemplo "post", entre la visualización y el juego de sonidos (por ende, movilidad de sentidos) Brossard trabaja un tapiz desterritorializado por la misma deriva incesante, por la "forma movediza" ${ }^{12}$ que aparece pero no es (el holograma mismo).

La kinesis se erige en llave del mundo: "La memoria es un teatro del cuerpo" (id. ibid.), porque el movimiento del cuerpo es igual al del pensamiento; es "l'harmonie qui fait sens" (Picture..., p. 47 para las dos últimas frases). Visualización y gesto: escribir equivale para Brossard a vivir, como la vida equivale a la ficción. ${ }^{13}$

El "yo" verbal, protagonista o escritora, se evade en la incertidumbre para la lectura. Desconcierto del lector: ¿quién es "yo"? Es la evasión misma; es la transferencia de un yo entre "túes" que se alternan incansablemente. El propósito de Brossard sigue el movimiento porque su escritura quiere "escapar a toda categoría negando (niant) // el espacio mismo y siempre fluido del instante" (Picture..., p.69). "Memoria: holograma del deseo" propone en la transferencia una deriva invertida: un regreso-contra-la-ley ${ }^{14}$. En la rara lengua que sería puente entre la lírica y el manifiesto, Brossard juega a contar a lo femenino entre "cuento = narración" y "cuento = cuentas" ${ }^{15}$, donde la retórica, la teoría y la lingüística en sí, de modo mallarmeano, tienen estrecha relación con esta prosa poemática o con el poema mismo: "...tal sabor de ficción // nuestras lenguas acurrucadas listas para saltar // motines semánticos // entre las paradojas y los días hermosos" (Vértigo... p. 19)

En la Nouvelle Barre du Jour a cargo de Jeanne Demers y Line Mc Murray ${ }^{16}$, 
aunque no muestren absoluto acuerdo con las feministas, las compiladoras escriben en el "Liminar":

Los textos / gestos femeninos se particularizaron más bien por una búsqueda [quête] múltiple (¿̨un juego?) de identidad como mujer, madre, amante, hija, hermana, artista, escritora, sindicalizada, quebequense y, más simplemente, "persona" (personne = "persona" y "nadie"). Las comillas son del original ${ }^{17}$

De esa quête lúdica proviene la eterna transferencia tanto del protagonismo como del espacio. Muchas veces el protagonismo no regresa al original; es transferencia (v. "Ella sería...”). En cuanto a la quebecidad, un aspecto problemático en la escritura del Canadá-nación, no está presente en la obra brossardiana; las transferencias de lugares y de lenguas, los sueños con -por ejemplo- Buenos Aires, mantienen como patria movediza y derivante -como alfombra mágica- la lengua de origen.

La memoria afecta en particular a un pueblo que es pero no tiene una esencia ni un espacio en particular ${ }^{18}$. La deriva y la transferencia aluden a una tarea importante, vital para la mujer: habitar cuerpos simbólicos, lenguas diversas y espacios y tiempos distantes ${ }^{19}$ siempre ligados a la escritura, identidad tan rizomática como ésta lo es en numerosas oportunidades. Ser "nadie", al estilo Odisea, tiene tantas consecuencias como la escritora lo expresa para el "ser mujer".

Relato como reversión de la historia oficial, "escritura (...) como recorrido exploratorio (...) continuum abierto" 20 , la tarea de Brossard es el constante fluir de conciencia y cuerpo, de memoria y deseo.

\footnotetext{
Notas

${ }^{1}$ La autora ha recibido muchos premios importantes: el muy representativo Athanase David y dos veces el premio Gobernador General. Es reiteradamente premiada.

${ }^{2}$ La "clasificación” genérica es muy problemática en esta obra. Nada es puro, por lo tanto no es fácil decir qué es qué, a menos que la misma autora acepte el "etiquetaje" del volumen. Buscando a Brossard en diccionarios literarios o accediendo a las publicaciones, podemos hablar de lo que ella denomina "théorie/fiction" (entre otros, L'amèr ou le chapitre effrité, Picture Theory, French Kiss nombrado como novela en uno de sus volúmenes -igual que se designa del mismo modo a L'amèr-); novela (Le désert manve, traducida al castellano, Baroque d'aube, también traducida, Sold-out, étreintelillustration, Hier, que aparecerá en el próximo octubre); poesía (Langues obscures, Au présent des veines, traducido como En el presente de la pulsación y editado bilingüe por Botella al Mar, Installations, también editado en francés y castellano por la UNAM, poemas en antologías...); teoría propiamente dicha (dirección y compilación de La théorie, un dimanche); ensayos trabajados como ficción y publicados como nonfiction ("She Would Be the First Sentence of My Next Novel", conferencia dada en EEUU, escrita en francés y cuya primera frase está en inglés, traducida por primera vez al español por B. Arancibia (compiladora) e Isabel D. de Justo (El Quebec tiene cara de mujer....) y recientemente sacado como volumen bilingüe por The Mercury Press Non-Fiction). Finalmente, menciono la curiosa pieza teatral colectiva La nef des sorcières, donde siete autoras insertaron un monólogo en una línea de composición, con la firma de cada una (digamos, asumiendo la autoría de cada breve obra).
} 
${ }^{3}$ Cf. por ejemplo el volumen de poesía D'arcs de cycle la dérive, grabado de Francine Simonin. Saint-Jacques-le-Mineur: Ed. de la Maison, 1979. ${ }^{4}$ Ver, también como ejemplo, en la p. 17 del original (l'Hexagone, 1995): "Las cinco sibilas de la capilla Sixtina..."). Mi traducción.

${ }^{5}$ Picture..., p. 53; v. Forsyth, L.H., p. 19 y Brossard L'amèr, Picture Theory, Baroque d'aube...

${ }^{6}$ Esto explica la necesidad de volúmenes bilingües.

7 “comme il arrive que l'ombre d'un doute // j'entre simultanément dans le hall d'entrée // (un je se perd ici au travail (...)”. Picture Theory, p. 65. La cita comienza sic en la página, como los poemas de En el presente de... ${ }^{8} \mathrm{~V}$. "l'/je force familière m'est désir si semblable (...)" Picture Theory, p. 37; "L’A Mèr", en página aún no numerada de L'Amèr, y no como ejemplo sino como "micromanifiesto" en Langues obscures: "Il faudra s'entendre sur l'intraduisible rencontre des mots et de la lumière acquiescée en nous quand je respire. Car chaque fois notre douleur invente en deca du langage, audelà, je vois que nous avons raison” (p. 58). La tipografía es de la autora.

${ }^{9}$ Por ejemplo, "l'illyssybilité", que además juega con la suma de sentidos evocados no sólo por el sonido sino también por la grafía. Picture..., p. 48. ${ }^{10}$ V. Dupré, L., p. 7.

${ }^{11}$ El original juega con los sonidos y la semántica: “...le sujet vit entouré de personnages et de personne." Journal..., p. 9.

${ }^{12}$ Brossard, Feminaria / 3, p. 7.

13 “...Anna sentait la fiction, sur son dos, j'anticipe.” Picture..., p. 45

14 "Referise es ser reenviada a, (...)". Feminaria /3, p. 8.

15 "cuenta regresiva en la historia de la humanidad"; "obliga a la que escribe a remontarse en el tiempo...". Feminaria cit.

${ }^{16}$ NBJ es al mismo tiempo revista y editorial. Brossard está entre sus fundadoras.

${ }^{17}$ Demers y Mc Murray: “Liminaire”, pp. 7-8.

${ }^{18} \mathrm{~V}$. "La memoria como referencia", "La memoria como crisol de resonancia", "La memoria como canto de visión", tres titulillos del artículo cit. en Feminaria / 3.

${ }^{19} \mathrm{Cf}$. en especial Journal intime...pp. 18-19 y, en general, el conjunto de textos fechados y localizados o no.

${ }^{20}$ A[licia] G[enovese], una de las traductoras de En el presente..., p. 9

\section{Bibliografía}

BROSSARD, N.: (1988), L'Amèr ou le chapitre effrité. Ed. revisada y corregida: col. Typo, l'Hexagone, Montréal, [1977].

(2000) En el presente de la pulsación / Au présent des veines. Edición bilingüe. Traducción y prólogo Cohen, S. y Genovese, A., Botella al Mar, Buenos Aires, [1999].

(1997) Instalaciones (con y sin pronombres), Ed bilingüe. Trad. de Manssur, M.. Trois Rivières: Écrits des forges, UNAM y Aldus, México D.F., [1989].

(1998) Journal intime, suivi de Oeuvre de Chair et Métonymies. Reedición del primero y edición de Oeuvre..., Les herbes Rouges, Montreal, [1984].

(1992) Langues obscures, l'Hexagone, col. Poésie, Montreal. 
"Memoria: holograma del deseo" en Feminaria / 3, pp. 7-9. Trad. de Solá, M.

(1989) Picture Theory, L'Hexagone, col. Typo, Montreal.

(enero-marzo 1991) "Tendons, paragraphes et voix (sic) lactée" en Revue des Sciences Humaines, T. LXXXXV (sic), p. 221.

(2000) Vertige de L'Avant-Scène - Vértigo del Proscenio. Ed. Bilingüe. Trad. De Manssur, M.. S/l (Trois-Rivières): Écrits des Forges Poésie, El Tucán de Virginia, México, [1997].

ARANCIBIA, B. (comp.): (1994) "Ella sería la primera palabra de mi próxima novela" en El Quebec tiene cara de mujer. Ensayos de mujeres sobre las letras del Quebec, Biblioteca Norte Sur, Rosario.

Demers, J. y Mc Murray, L.: (1987), Femmes scandales, 1965-1985, s/l: nbj. Dupré, L.: "Préface. Du propre au figuré” en L'Amèr..., pp. 7-13 